\title{
EPP IN T: MORE CONTROVERSIAL SUBJECTS
}

\author{
Samuel David Epstein, Acrisio Pires, and T. Daniel Seely
}

\begin{abstract}
This paper has two goals. First, it provides a solution to an important and particularly recalcitrant problem regarding non-control infinitival complements of derived nouns, which have been argued to provide independent motivation for the retention of the EPP in T. Second, it presents an unnoted problem regarding the elimination of the EPP in infinitival complements of underived nouns, proposing an analysis for them that need not appeal to the EPP in T. To reach these goals, this paper appeals to: (i) an approach to null complementizers as affixes that require specific kinds of hosts, as proposed in Bošković and Lasnik 2003 (building on, but modifying certain aspects of the foundational analysis in Pesetsky 1991 and Stowell 1981); and (ii) an argument (based on Ormazabal 1995) that non-control infinitival complements to nouns are CPs headed by an affixal null $\mathrm{C}$.
\end{abstract}

\section{Introduction}

We attempt to provide a solution (without appealing to the EPP) to an important type of particularly recalcitrant problem-involving non-control infinitival complements of nouns - that has been argued to provide independent motivation for the retention of the EPP (Extended Projection Principle) in T(ense). Such data might be called (part of) the "residue of EPP in T." We appeal to an approach to null complementizers as affixes, originally proposed by Pesetsky (1991) (also considering proposals in Stowell 1981) and partially modified by Bošković and Lasnik (2003). We also adopt a hypothesis from Ormazabal 1995 that non-control infinitival complements of nouns are CPs. Our central proposal is that certain ungrammatical non-control infinitival complements to nouns, thought to motivate EPP in T, can be independently excluded because they are headed by an affixal null $\mathrm{C}$ that fails to find an appropriate host. In section 1 we present what we take to be a crucial background discussion about the motivation for the EPP. We do not seek to provide a comprehensive analysis of null complementation in English here, nor

* Željko Bošković gave a talk at the University of Michigan in December 2003, and we had a chance to talk with him about some of the material presented in this paper. We are very grateful for his helpful and open-minded discussion and for his written comments on an earlier version of this paper. We also thank Noam Chomsky, Sam Gutmann, Norbert Hornstein, David Lightfoot, Javier Ormazabal, Hamid Ouali, Esther Torrego, and particularly David Pesetsky for extremely detailed and very helpful written comments on an earlier draft, not all of which we were able to comprehensively address here. Thanks also to Duk-Ho An and Heles Contreras for sending us their manuscripts concerning the EPP. Thanks also to Catherine Fortin for excellent comments on the paper and for helping us with revisions in a prefinal version of the manuscript. This work was presented to the University of Michigan/Eastern Michigan University syntax research group in March 2005, and we thank the audience for helpful discussion. Finally, we also thank three anonymous Syntax reviewers for insightful and helpful comments. Authors are listed alphabetically. Please send comments to all three authors. 
do we address a number of other important analyses of such phenomena (see, e.g., Pesetsky \& Torrego 2001, 2004; Anderson \& Lightfoot 2002; Lightfoot 2002). In particular, we put aside the question whether an approach to null complementizers requires the adoption of an EPP feature in C. ${ }^{1}$ Rather, in section 2 we focus on the unnoted consequences of an approach to null complementizers as affixes for the possible elimination of the EPP in T. In section 3, we also present some data of our own regarding null complementation that we believe has not been noted previously and discuss its relevance to a theory of null complementizers and syntactic relations within extended clause structure more generally.

\section{On the EPP}

\subsection{The Mysteriousness of the EPP}

It has recently been claimed that "the EPP has been... a pervasive mystery since it was first formulated by Chomsky (1981)" (Lasnik 2002:1). We agree. There is but one general strategy within rational scientific inquiry for overcoming the postulation of such ill-understood principles: try to clarify them so as to clarify the predictive content and explanatory depth of the theory. (The methodological issue of when to address which unclarity is, of course, open to debate.) One form of clarification is elimination. The mysterious EPP can be clarified to the extent that it is eliminated. Attempting to eliminate the EPP will, at best, allow us to deduce the EPP's properties and effects from independently motivated mechanisms, regarding the specification of lexical (e.g., morphophonological) properties and their legitimacy at the interfaces. At worst, the attempt will have the "therapeutic value" (Chomsky 1995) of determining which of the EPP's properties and effects can (and perhaps cannot) be deduced.

\subsection{Unclarities in the Formulation of the EPP}

Note, first of all, that the formulation of the EPP raises serious questions. Originally, it was a configurational requirement, as expressed by a phrase structure rule, that clauses have a subject (Chomsky 1981). But a problem with this statement of the EPP is that it represents a form of construction specificity of just the sort that, for principled reasons, is avoided within the principles and parameters and, more recently, the minimalist approaches, which seek to reduce such requirements to features of heads, as locally manipulated by the generative procedure. This, in turn, is consistent with a derivational minimalist explanation (see Epstein 1994, 1999; Berwick \& Epstein 1995; Epstein et al. 1998; Epstein \& Seely 2002, forthcoming). Indeed, within the minimalist approach of Categories and Transformations (Chomsky 1995), the EPP shifts from a requirement on

\footnotetext{
${ }^{1}$ In a different paper (Epstein, Pires \& Seely, 2004), we question the postulation of an EPP feature in (null) C, as implemented by Bošković and Lasnik (2003). See also Contreras 2003 for critical discussion on the EPP in C.
} 
clausal structure to a requirement on feature checking; thus it shifts to a morphosyntactic property. The basic idea is that there is some feature, an "EPP feature," which attracts a DP to specifier position. This attractively subsumes the EPP under the more general feature checking mechanisms of Case and agreement. But the problem is that it is unclear just what this EPP feature is: Categories and Transformations argues that it is a D-feature, whereas it is suggested in other work (Chomsky 2001) that it is a person feature. Moreover, once specified, we still have the question of the level of application of the EPP: Is it derivationally satisfiable (Lasnik 2002)? Is it an Everywhere principle (Chomsky 1995:123)? ${ }^{2}$ Or is it (at least) a PF requirement, which, as we argue in Epstein, Pires, and Seely 2004, might be entailed by Bošković and Lasnik 2003 ? Additional problems in the formulation of the EPP arise with the recent reemergence of the EPP as a structural requirement (see Lasnik 2001 and Chomsky 2001, 2002). Yet a further issue is that the EPP has been argued to be neither featural nor configurational but instead a "semantic" requirement on theme-rheme or information structure (see Rothstein 1983 and Williams 1980).

This leaves unclear what the formulation of the EPP is. Moreover, its crosslinguistic status is in question. For example, Alexiadou and Anagnostopoulou (1998) argue that the mechanisms by which the EPP is satisfied are parameterized, whereas others do not assume so. Needless to say, there are also empirical problems confronting the EPP (e.g., Castillo, Drury \& Grohmann 1999, Epstein \& Seely 1999, McCloskey 1997), some of which we will note below.

\subsection{Redundancy with Other Principles}

The EPP has in its many varying and unclear forms been deemed by various researchers to be not only mysterious but, to the extent that it is clear, highly redundant with other principles of Universal Grammar (see Fukui \& Speas 1986, Lasnik \& Uriagereka 1988, and especially Martin 1999). These include:

(1) a. Obligatory Case discharge theories: requiring subjects of finite T/I under Spec-head agreement (Fukui \& Speas 1986 and Martin 1999) renders EPP unnecessary/redundant for finite clauses.

b. Spec-head agreement theory, perhaps also requiring subjects in finite clauses. ${ }^{3}$

c. Theta theory (Rothstein 1983; see also Epstein \& Seely, forthcoming:chap. 4, extending ideas by Moro 1997 according to which certain instances of expletive $i t$ are in fact predicates).

d. The theory (or theories) of movement, forcing landing sites by locality (see Chomsky 1975 for Subjacency, and Bošković 2002 for Minimal Link Condition; and see discussion below).

\footnotetext{
${ }^{2}$ Thanks to Hamid Ouali (p.c.) for pointing this out to us.

${ }^{3}$ As pointed out by a reviewer, Case and agreement checking are not redundant with the EPP under a Probe-Goal Agree relation, whereby Case and agreement on argument DPs can be checked without movement (Chomsky 2000, 2001).
} 
e. Null Complementizer theory: we argue here that the EPP is also rendered redundant over a thus far unnoted domain - namely, "EPPeffects" in non-control infinitival complements of underived nouns. We propose this domain is in fact covered by an approach to null complementizers as affixes (Bošković \& Lasnik 2003, Pesetsky 1991, Ormazabal 1995:chap. 2, 136).

\subsection{The Attempt to Eliminate the EPP}

Given the unclarity of the EPP, and its apparent redundancy with a number of independently motivated principles, it seems a worthwhile exploration to try to eliminate it, consonant with a derivational approach under which we try to deduce all tree properties from the local combinatorial features of atomic lexical elements. Of course, we do not claim to have eliminated the EPP, given that we do not address, for example, clause structure in a range of different languages (see, e.g., Alexiadou \& Anagnostopoulou 1998). In fact, if "possible human knowledge state" is our object of inquiry, we cannot explore all cases. Rather, we hope to thoughtfully explore the possible elimination of an empirically unclear principle, which to the extent that it is clear, appears to be redundant, and moreover incompatible (on some of its many disparate formulations), with the attempt to explain tree structures by virtue of formulating a theory containing no tree-based (molecular) structural requirements - that is, a generative explanation.

\section{A Null Complementizer Approach and Its Possible Role in the Elimination of the EPP}

To address our main points, let us first briefly review the basic properties of the Bošković and Lasnik (2003, hereafter B\&L) analysis by examining their account of simple finite cases of obligatorily overt complementizer phenomena. B\&L propose a theory of null complementizers that assumes, among other things, that:

(2) a. The English lexicon contains null complementizers that are (PF) affixes, each of which requires specific kinds of lexical hosts. ${ }^{4}$

b. Affix hopping is PF merger.

c. PF merger requires adjacency at PF.

\footnotetext{
(i) They do-PRES.PL not live in Chicago.

(ii) *They PRES.PL not live in Chicago.

(iii) They live+PRES.PL in Chicago.
}

${ }^{4}$ Duk-Ho An (2003) and Noam Chomsky (p.c.) suggest that there may be potential problems with the claim that there are phonologically null affixes that require a PF host. We do not address this issue in detail in this paper. Notice, however, that there are other elements that have been taken to have similar properties. This is the case with the Inflectional head in cases that require $d o$-support in English, in which do is taken to be inserted to support an affixal inflectional head, even though the head itself may not be phonologically realized, as in (i) (see, e.g., Chomsky 1957, Lasnik 1999): 
B\&L account for the ill-formedness of structures such as (3), which lacks the complementizer that.

(3) *It seemed at that time [CP C [TP David had left]].

$(B \& L(3 a))$

They argue that these constitute a "stranded affix" violation: the null $\mathrm{C}$, which in this case is by hypothesis an affix that requires a $+\mathrm{V}$ host, is not adjacent to $\mathrm{a}+\mathrm{V}$ category at PF. Building from this, B\&L hypothesize that there are various null Cs, differing in their feature matrix, and in this way they account for a range of null complementizer phenomena. $^{5}$

\subsection{A Null Complementizer Approach Readily Extended to Infinitival Complements of Nominals}

In this section we argue that there is an important, but unnoted, consequence of the approach to null complementizers as affixes, given some of the recent modifications to this approach in B\&L: it allows us to eliminate appeal to the EPP in T in a domain wherein the retention of the EPP has been argued to be necessary. Our argument is this: We adopt the independently motivated hypothesis that non-control infinitival complements are CPs (see Ormazabal 1995:chap. 2 and, for additional discussion, Bošković 1997). Given that, along with Pesetsky's (1991) claim that the null C is an affix, we can account for the likes of (4a) under B\&L's approach, without any appeal to EPP in T to "brutishly" force a subject.

(4) a. *The conjecture [

to seem that Bill left] is ludicrous.

b. The conjecture [that it seems that Bill left] is ludicrous.

It has been argued that the ill-formedness of (4a) cannot be attributed to the Inverse Case Filter (i.e., it cannot be due to the appearance of an unvalued Case feature at LF, since neither the noun conjecture nor the form of to in (4a) bears Case); and it cannot be attributed to Theta theory (even under VPexternal subject analyses) because the complement of conjecture contains a raising predicate. Consequently, (4a) is argued to implicate the EPP in T. The EPP excludes (4a) because there is no subject (at PF). Moreover, if a subject - for example, an expletive - is inserted so as to satisfy the EPP, that derivation crashes, because the Case feature of the expletive remains at LF. However, we will suggest that, given a certain set of assumptions compatible

\footnotetext{
${ }^{5}$ Pesetsky and Torrego $(2001,2004)$, and Anderson and Lightfoot (2002) propose detailed and very insightful analyses of a range of different phenomena related to null $\mathrm{C}$. However, both Pesetsky and Torrego's and B\&L's analyses rely on an EPP specification for C to account for some of the relevant phenomena. See An 2004 for possible problems for Pesetsky and Torrego's analysis. See Epstein, Pires, and Seely 2004 for possible problems confronting the proposal made by $\mathrm{B} \& \mathrm{~L}$ that (null) $\mathrm{C}$ is specified for $\pm \mathrm{EPP}$.
} 
with aspects of the null complementizer approach proposed in B\&L, (4a) violates the Stranded Affix Constraint, as there is an affixal null C in (4a) that cannot find an appropriate host. The complete analysis is provided below. In the next section, we summarize Martin's (1999) analysis of raising infinitival complements of derived nominals such as belief. We then turn to our main focus-raising infinitival complements of nouns like conjecture-which to our knowledge thus far have not been analyzed in a way that is compatible with the elimination of the EPP.

\subsubsection{Is the EPP necessary to exclude non-control infinitival complements of nominals?}

As we noted, Epstein \& Seely (1999, 2002, forthcoming) and a number of other researchers have argued for the possible elimination of appeal to the EPP in generating A-raising structures (e.g., Fukui \& Speas 1986; McCloskey 1997; Martin 1999; Castillo et al. 1999; Boeckx 2000; Grohmann, Drury \& Castillo 2000; Chomsky 2001; and Bošković 2002). One domain where the attempted elimination of the EPP is problematic concerns non-control infinitival raising complements of nominals, as in (5).

*The belief [ to seem that [Peter is ill]] upset Mary.

(see Bošković 1997, ${ }^{6}$ Martin 1999)

Unlike the analogous ungrammatical case with the Accusative-assigning verb believe appearing in place of belief, here we cannot appeal to obligatory Case discharge to rule out example (5), given that belief lacks Case. ${ }^{7}$ In fact, Lasnik (2002) argues that (5) provides strong motivation for the EPP. If there is an EPP requirement that the specifier of the lower TP be filled, and if there is no null expletive in English, then (5) is ruled out as an EPP violation. To satisfy the EPP, some overt nominal must occupy the spec of TP position, but then a Case Filter violation results, assuming the expletive bears unchecked Case in (6) (see Chomsky 1981; Belletti 1988; Lasnik 1992, 1995; Bošković 1997, 2002; and Epstein \& Seely 1999, forthcoming).

\footnotetext{
${ }^{6}$ Bošković (1997) is the first to argue for the EPP on the basis of examples like (5), and he provides a more comprehensive paradigm than the one we present here; see Bošković 1997 for further discussion. Bošković (2002), on the other hand, argues against the EPP but presents (5) as problematic for the elimination of the EPP. He argues that the cases, besides (5), that purportedly motivated the EPP are redundantly ruled out by independently motivated principles of the grammar and hence that the EPP "should" be eliminated. Bošković (2002:176), in fact, points out that "the EPP seems to be the only formal requirement on the target that is apparently not allowed to drive movement," and thus that the EPP "simply does not make sense." See also Martin 1999 for important discussion. Bošković (2002) points out that (5) is disallowed under the "Activation Condition" of Chomsky 2001; the defective EPP probe to Matches with the local DP Peter, but Agree cannot operate since the goal Peter has already had its Case feature checked and hence is "inactive."

${ }^{7}$ On inherent genitive Case, see Bošković 1997. See also fn. 18 below.
} 
With respect to the EPP-based analysis of (5), Lasnik (2002:5) states:

Descriptively, it is certainly true that nouns never take such complements [i.e., infinitival complements of the non-control type]. But in the absence of a better account of the fact, it seems most principled to rely on the combination of the Case filter and the EPP.

What Lasnik (2002) does not discuss is that there is an independently motivated account of (5) that does not appeal to the EPP. Martin (1999) suggests that (5) is excluded because it ultimately violates Myers' Generalization (Myers 1984). Martin's basic analysis runs as follows: (i) a nominal like belief is derived (in the syntax/morphology) from its verbal root and that root takes a full CP complement, which in this case has a null complementizer; (ii) following Pesetsky (1991), Martin assumes that this null complementizer is an affix; (iii) the affix incorporates into the verb believe; and (iv) the believe $+\mathrm{C}$ element is then input to the nominalizing affix. However, by Myers' Generalization, a zero-derived element (like believe $+\mathrm{C}$ ) cannot host a derivational affix (see also Allen 1978). Hence (5) and (6) ${ }^{8}$ are correctly disallowed by the independently motivated Myers' Generalization, and there is no need to appeal to the EPP.

Martin's (1999) Myers-style analysis of (5) derives a proper subset of the cases that support the descriptive generalization that nouns never take infinitival complements of the non-control type. For Martin, in any case equivalent to (7) the null complementizer (assumed to be an affix) must incorporate into the verb (otherwise the "stranded affix constraint" will be violated):

$$
\text { verb [CP } \varnothing\left[\mathrm{TP}_{\mathrm{P}} \text { to } \mathrm{non}_{\text {control } \cdots]}\right]
$$

But then the verb $+\mathrm{C}$ is a zero-derived word that cannot be nominalized because the nominalizing affix is derivational and derivational affixes cannot take a zero-derived word as host, by Myers. ${ }^{9}$

\subsubsection{An unnoted problem: Non-deverbal nouns?}

Interestingly, Martin (1999) does not consider another possibility. Suppose that the $\mathrm{N}$ head taking a $\mathrm{CP}$ complement is not a deverbal nominal but in fact an underived nominal:

(8) noun $\left[\mathrm{CP} \varnothing\left[\mathrm{TP}_{\mathrm{T}}\right.\right.$ to ${ }_{\text {non }}$ control $\left.\left.\cdots\right]\right]$

\footnotetext{
${ }^{8}$ Note that (6) is also out for Case reasons.

${ }^{9}$ Ormazabal (1995:128, fn. 45) notes that Lasnik (p.c.) observes that the success of the analysis rests on rule ordering: first the null $\mathrm{C}$ incorporates, then subsequent derivational affixation of the nominalizing affix is blocked by Myers' Generalization. However, the opposite ordering is not blocked. See Ormazabal 1995 for analyses blocking a derivation in which nominalization precedes zero-affixation.
} 
In this case, there would be no violation of Myers' Generalization; rather, the null $\mathrm{C}$ incorporates into the non-zero-derived noun, and the result is (ceteris paribus) predicted to be well formed. ${ }^{10}$ In fact, however, it is not well formed. To illustrate this, note to begin with that Martin (1999) argues that (9) (a verbal case not equivalent to (8)) is excluded because the verb conjecture is derived from the noun conjecture.

*Bill conjectured [ to seem that Fred left].

Thus, in (9) the null $\mathrm{C}$ incorporates into the noun conjecture to yield the zeroderived word conjecture $+\mathrm{C}$; but this zero-derived element is then, by Myers, not accessible to the verbalizing derivational affix. ${ }^{11}$ Thus, for Martin, it is required that the verb in (9) be derived from the noun, ultimately leading to a violation of Myers' Generalization in this case. ${ }^{12}$ Crucially then, Martin clearly assumes that the noun conjecture is not derived from the verb. But, unnoted in Martin 1999 is that (10) is ungrammatical.

*The conjecture [ _ to seem that Fred left] is ludicrous.

Under Martin's analysis it is unclear why (10) is ungrammatical. Specifically, (10) does not seem to violate Myers' Generalization. This is because it is the verb conjecture (as in (9)) that is zero derived from the noun, hence we assume the noun conjecture is not zero derived. Thus, in (10) the null $\mathrm{C}$ incorporates into the underived noun conjecture, and there is no violation of Myers' Generalization. ${ }^{13}$

10 Ormazabal (1995:136, citing Bošković, p.c., and Chomsky 1970) notes that underived nominals are also incompatible with the null complementizer, yet being underived they escape Myers. As in:

(i) *Their hypothesis [Ø neural nets are not connected]. (Ormazabal 1995, chap. 2: (108b))

But see footnote 14 .

${ }^{11}$ More explicitly, Martin (1999) generates the derived verbs he analyzes via incorporation of the nominal form into a light $v$. Extended to the case at hand, the verb conjecture is derived from $v+$ conjecture (interpreted roughly as "make a conjecture") (see also Hale \& Keyser 1993).

${ }_{12}$ An alternative approach to examples like (9) is to assume that conjecture is not a member of the BELIEVE-class. That is to say, conjecture does assign accusative Case. Evidence for this is provided by Epstein and Seely, forthcoming, in the form of examples like:

(i) John conjectured Mary's illness to have upset Fred.

(9) would then be excluded because there is no DP present to receive accusative Case from conjecture. Martin (1999) makes the more general suggestion that there are no BELIEVE-class verbs.

${ }^{13}$ B\&L note an empirical problem for the Pesetsky (1991) null-complementizer analysis (using Myers' Generalization) of examples like (5) (*the belief [_to seem that Peter is ill] upset Mary); specifically, B\&L argue that the analysis does not extent to nonderived nominals like *the fact $C$ Mary left. Given that the noun fact is not derived, there is no possibility of violating Myers' Generalization. B\&L state that, to account for *the fact C Mary left, they would have to appeal to the "complicating assumption that all nouns are derived when taking a clausal complement" (p. 534-535). What (10) shows, however, is that it is more than a "complicating assumption." In fact it may be impossible to derive all cases under that assumption, (10) being the case in point, 
So, even with Martin's analysis of (5) and (6), it would seem that (10) is an important remaining argument (a "loophole") motivating appeal to the EPP. With the EPP, (10) is out, given that the specifier of the lower TP (i.e., the specifier of to) is empty.

In the following section, we argue that an approach to null complementizers as affixes excludes (10) and does so without appeal to the EPP in T.

\subsection{An Unnoted Consequence of an Approach to Null Complementizers as Affixes}

Bošković and Lasnik (2003) propose a theory of null complementizers that makes the assumptions in (2). Under those assumptions, B\&L account for the ill-formedness of (3), in which by hypothesis an affixal null complementizer is stranded, having no adjacent $+\mathrm{V}$ host.

Consider again (10). One unnoted consequence of the B\&L analysis is as follows. First, following Ormazabal (1995), suppose the infinitival complement to the noun conjecture in (10) is a CP projection. Consequently, there is a null complementizer present. By hypothesis, it is [+affixal]. Now the example is excluded not because we need to have a subject, but because we have a [+affix] null complementizer requiring an adjacent $+\mathrm{V}$ host. This provides an independently motivated account that excludes the critical example (10) without appeal to the EPP in $T^{14}$

*The conjecture $\left[{ }_{\mathrm{CP}} \mathrm{C}[\ldots\right.$ to seem that Fred left $\left.]\right]$ is ludicrous.

Assuming that the null $\mathrm{C}$ in this case is an affix that requires a $+\mathrm{V}$ host, then (10) is out because the noun conjecture cannot host the complementizer. ${ }^{15}$

because here we have a noun from which the verb is derived, hence the noun itself is by hypothesis underived, immunizing this data from a Myers-style account. Cati Fortin (p.c.), however, points out another logical possibility. It could be the case that the verb is derived from the noun, yet the noun is nonetheless itself derived from some "more abstract" form. Here, we do not pursue this alternative.

${ }^{14} \mathrm{~B} \& \mathrm{~L}$ analyze only finite complements of Ns. Regarding infinitival complements to Ns, they defer to Bošković 1997, noting only that null complementizer licensing in infinitivals "does not arise because of interfering factors.” However, neither Bošković 1997 nor Ormazabal (1995, p.c.) explicitly address cases like (10) — in which we have an infinitival raising complement — and their relevance to the EPP.

15 Ormazabal (1995) argues that non-control infinitive complements to derived nouns can not be uniformly excluded by Case theory (nor by ECP, or chain requirements). Rather, they are uniformly excluded because the infinitive complement is a $\mathrm{CP}$ headed by a null $\mathrm{C}$ which is invariably stranded as an affix, as in the following

(i) *John's belief (of) [CP NULL-C [Mary to be intelligent]]

(ii) *John's belief [CP NULL-C [Mary is intelligent]] (Ormazabal 1995:55)

This is of direct relevance to us since under our proposed elimination of the EPP, the examples discussed in text, can't be excluded by Case theory, nor can we appeal to the EPP to exclude them. However, under Ormazabal's unified and empirically motivated null-C analysis, the examples we present here can be excluded as stranded affix violations without appeal to EPP. Crucially, Ormazabal was not concerned with the elimination of the EPP in proposing his analysis. 
Indeed, in relevant respects, (10) is similar (except for the [-tense] of the lower CP) to B\&L's example (13) (p. 534):

*I heard about the fact C Mary did it.

(B\&L 2003, (13))

In (11) the affixal null complementizer requires a $+\mathrm{V}$ host and so cannot take the adjacent noun fact as its host, and thus the null affix complementizer is stranded. ${ }^{16}$

In fact, it seems that this kind of analysis can derive the descriptive generalization (see (6)) that there is no noun that can take a raising (noncontrol) infinitival as its complement. In earlier work, as previously discussed, Lasnik (2002) claimed that this descriptive generalization follows from the EPP; that is, in (10) to requires a Spec,TP, so (10) is out as an EPP violation (and if we fill the Spec,TP with an overt expletive, there will be a Case Filter violation). But, given that the null affix $\mathrm{C}$ account is independently motivated (as B\&L argue), then we have yet another redundancy between the EPP and independently motivated principles. One obvious path to follow, then, is to eliminate the EPP's utility in this loophole case as well. As we have shown, we can account for (10) without the EPP. Note further that B\&L need the null affixal $\mathrm{C}$ analysis to account for the ill-formedness of (12).

*The conjecture [C [it seems that Fred left]] is ludicrous. (cf. The conjecture that it seems that Fred left is ludicrous.)

Presumably, what blocks (12) is the fact that the null affixal C cannot affix to the $\mathrm{N}$ conjecture; but our point is that the very same analysis cannot be prevented from automatically extending to (10) (in which there is also a CP, according to Ormazabal's proposal), rendering the EPP unnecessary to exclude this case..$^{17,18}$

${ }^{16}$ A reviewer notes the very interesting grammatical example:

(i) John seemed at the time [ $t$ to be demented].

If there is a null $\mathrm{C}$ here, it apparently can successfully affix to the adjacent noun time, unlike in (13) and the following, which are ungrammatical:

(ii) *It seemed at that time [CP C [IP David had left]].

See B\&L for further discussion of the finite case (ii) and Epstein, Pires, and Seely 2004 for other potential problems concerning B\&L's treatment of extraposition.

${ }^{17}$ We should note that for some speakers (10) is worse than (12). Thus, it could still be argued that the EPP is necessary on the grounds that both (10) and (12) violate the stranded affix constraint, but (10) is worse because it also violates the EPP. We thank Željko Bošković (p.c.) for helping us to clarify this point. At the very least then, why are pure EPP violations so hard, if not impossible, to identify?

${ }_{8}$ Note further that Bošković (1997) accounts for cases like *John's belief/proof to have John left by appealing to Chomsky's (1986) genitive Case analysis: John cannot be assigned genitive Case (which is inherent) because there is no $\theta$-relation between John and the higher N. So, again, there would be yet another redundancy with the EPP. (However, see Ormazabal 1995:sect. 2.4.2 for possible limitations of Chomsky's [1986] analysis, in particular its failure to extend to Romance infinitives. The Romance infinitives' ill-formedness indicate "the problem is not the impossibility of Case assignment to the infinitival subject, but rather the infinitival complement itself" [Ormazabal 1995:119].) 


\subsection{Further Issues for the Null C Analysis in Non-Control Infinitival Complements of Ns}

\subsubsection{A note on nonfinite relative clauses}

A first-blush problem for our extension of the $B \& L$ analysis to account for (10) involves (13).

(13) The man C to visit is Bill.

Example (13) suggests that if there is a null $\mathrm{C}$ in infinitival relative clauses, that null $\mathrm{C}$ can take an $\mathrm{N}$ as its host $(\mathrm{B} \& \mathrm{~L}$ claim that relative null $\mathrm{C}$, as in the man C Mary saw is in fact a null $\mathrm{C}$ that can take $\mathrm{N}$ as host). But if the null relative $\mathrm{C}$ can take $\mathrm{N}$ as its host, then the null $\mathrm{C}$ can be hosted by man in (14), the relative clause analogue of the nominal complement cases (compare (10)) hitherto argued to require the EPP.

*[The man $[\mathrm{C}[\ldots$ to seem that Mary is smart $]]]$ is Bill.

Why, then, is (14) out? The EPP would do the trick. In fact, (14) would apparently be one of the last cases where the EPP would be needed. However, note that (14) is out because to seem that Mary is smart cannot be predicated of man: the relative clause has no $\theta$-role to give (independently of (14) we need a $\theta$-relation between the relative clause and the relative head: ${ }^{*}$ The man for it to seem that Mary is smart is Bill). So, (14) is out as a theta problem, without appeal to the EPP after all. Here, we see a redundancy between Theta/ Predication theory and the EPP.

However, as David Pesetsky (p. c.) points out to us, this account does not completely generalize. Consider the following (due to Pesetsky):

(15) a. The man for it to seem that we visit most often is Bill.

b. *The man to seem that we visit most often is Bill.

For Pesetsky, (15b) is worse than (15a). If there is no EPP, and if relative null $\mathrm{C}$ can be hosted by $\mathrm{N}$, it is unclear why (15b) should be out - there is no theta problem of the sort in (14). The relative clause can be "predicated" of the head $\mathrm{N}$ through the empty relative operator originating as the object of visited (cf. The man who it seems that we visited most often is Bill). We note further that a similar contrast emerges with tough-constructions. Consider:

(16) a. Bill is quite difficult for it to seem that we visited.

b. *Bill is quite difficult to seem that we visited.

c. Bill is quite difficult to visit.

It does not appear that we can appeal to the null $\mathrm{C}$ to rule out (16b), given (16c). If we exclude (16b) by claiming that there is a null $\mathrm{C}$ that cannot take an 
adjective as host, then we would apparently incorrectly rule out (16c). So, it is unclear whether the null $\mathrm{C}$ approach can also extend to all cases of nonfinite relative clauses. ${ }^{19}$

\subsubsection{A note on control complements}

Another issue regards control complements to nouns:
a. the pressure $\mathrm{C}$ to win
b. the desire $\mathrm{C}$ to win

Why are the phrases in (17) good? If there is a null C here-as in (10) and (14)-(16) - and if that null $\mathrm{C}$ cannot take $\mathrm{N}$ as its host, then the phrases in (17) should be out. Note, however, there is extensive argument (see Ormazabal 1995, Bošković 1997, Pesetsky 1991) that control infinitives are bare IPs, not CPs, and thus there is in fact no $\mathrm{C}$ at all, hence no null $\mathrm{C}$, in (17). This too comports with a theory seeking to eliminate appeal to government (see also Epstein 1998, 1999) and instead appealing only to lexical featural properties and local combinatorial requirements on them. Thus, there is a principled distinction between (10) and (14)-(16) on the one hand, and (17) on the other hand; in the former there is a null $\mathrm{C}$, but in the latter (by independent arguments) there is by hypothesis no $\mathrm{CP}$ projection, hence no null $\mathrm{C}$ present at all.

In this section, we have argued that the coupling of independently motivated proposals - namely, an approach to null complementizers as affixes as proposed by Pesetsky (1991) and modified by B\&L; and Ormazabal's (1995) analysis of non-control infinitival complements of nouns as CPs-allows us to derive, without any appeal to the EPP, the generalization that nominals never take non-control infinitival complements. $^{20}$

${ }^{19}$ It should be noted that the relative acceptability of (15) and (16a,b) is unclear for some speakers, including two of the authors. A reviewer writes, "Examples (14)-(15) do not seem to be problematic. (13) indicates that we are dealing here with a null Case environment (i.e., relative clause complements are PRO infinitives). Depending on whether or not Spec,IP of the infinitive is filled by PRO, $(15 \mathrm{~b})$ is then ruled out either via the Inverse Case Filter (because the null Case of the infinitival I cannot be checked) or by the well-known ban on expletive PRO. (16) can also be handled along these lines." One question to address regarding this analysis is how to ensure the presence of null Case-checking to in the head of the relative clause TP. Specifically, how can selection be operative in relative clauses, if relative clauses are adjuncts? We tentatively suggest here that null $\mathrm{C}$ cannot select a defective (raising) $\mathrm{T}$.

Furthermore, there are empirical problems for the null Case approach to Control, regarding for instance the relation between null Case and the Tense specification of infinitivals (see Pires 2001a,b).

${ }^{20}$ Interestingly, B\&L themselves adopt the EPP as one component of their full analysis of null complementizers. In Epstein, Pires, and Seely 2004, we argue that their appeal to the EPP in C, in fact, causes significant difficulties internal to B\&L's own analysis. 
As a final note, a reviewer rightly notes that there is a partial overlap between a Myers-style analysis and the one proposed here. Example (5) is out by both analyses (Myers', because belief is a derived noun, and ours, because the noun belief cannot host a null $\mathrm{C}$ in the complement clause) ${ }^{21}{ }^{21}$ However, (10) is out only because the null C in the complement clause cannot be hosted by a noun (it is not out by Myers' Generalization, because the noun is underived). Conversely, (9) is out only because the verb is derived, yielding a violation of Myers' Generalization.

\section{Conclusion}

In this paper we examined the analysis of null complementizers presented by Bošković and Lasnik (2003), modifying proposals by Pesetsky (1991) and Stowell (1981), as it relates to the current debate regarding the status of the EPP in T. We argued that an approach to null complementizers as affixes, combined with an analysis of certain non-control infinitivals as CPs (Ormazabal 1995), provides a solution to an important type of unnoted data that might be (mis?)taken to motivate the retention of the EPP in $\mathrm{T}$-namely, certain cases of non-control complements of underived nominals that escape a violation of Myers' Generalization, under Martin 1999.

In the course of our investigation, various previously unnoted data were introduced and their relevance to the question of the EPP in T was outlined. If we are on the right track, the domain of application wherein the EPP applies nonredundantly is even further reduced and the EPP may be eliminable (as argued in, for example, McCloskey 1997; Epstein \& Seely 1999, forthcoming; Fukui and Speas 1986; Boeckx 2000; Castillo et al. 1999; Martin 1999; Bošković 2002; and references therein), a welcome result regarding "a pervasive mystery."

\section{References}

ALLEN, M. 1978. Morphological investigations. Ph.D. dissertation, University of Connecticut, Storrs.

AlEXIADOU, A. \& A. ANAGNOSTOPOULOU. 1998. Parameterizing Agr: Word order, V-movement, and EPP-checking, Natural Language \& Linguistic Theory $16: 491-531$.

AN, D.-H. 2003. Sometimes in [Spec, CP] and sometimes not? Ms., University of Connecticut, Storrs.

${ }^{21}$ Notice, however, that null $\mathrm{C}$ in relative clauses can be hosted by a noun. Consider:

(i) The man to visit is John.

(ii) The man you visited is John.

These cases raise possible problems for $\mathrm{B} \& \mathrm{~L}$, concerning the need to appeal to constructionspecific (relative clause) properties regarding the licensing of null $\mathrm{C}$ by a noun host (see Epstein, Pires \& Seely 2004 for discussion). 
AN, D.-H. 2004. Clauses in non-canonical positions in PF. Ms., University of Connecticut, Storrs.

ANDERSON, S. R. \& D. W. LIGHTFOOT. 2002. The language organ: Linguistics as cognitive psychology. Cambridge: Cambridge University Press.

BELLETTI, A. 1988. The case of unaccusatives. Linguistic Inquiry 19:1-34.

BERWICK, R. \& S. D. EPSTEIN. 1995. On the convergence of "minimalist" syntax and Categorial Grammar. In Algebraic methods in language processing 1995: Proceedings of the twentieth Workshop on Language Technology 10. Enschede, the Netherlands: Universiteit Twente.

BOECKX, C. 2000. EPP eliminated. Ms., University of Connecticut, Storrs.

BOŠKOVIĆ, Ž. 1997. The syntax of nonfinite complementation. Cambridge, Mass.: MIT Press.

BOŠKOVIĆ, Ž. 2002. A-movement and the EPP. Syntax 5:167-218.

BOŠKOVIĆ, Ž. \& H. LASNIK. 2003. On the distribution of null complementizers. Linguistic Inquiry 34:527-546.

CASTILLO, J. C., J. DRURY \& K. K. GROHMANN. 1999. Merge over Move and the Extended Projection Principle. University of Maryland Working Papers in Linguistics 8:66-103.

CHOMSKY, N. 1957. Syntactic structures. The Hague: Mouton.

CHOMSKY, N. 1970. Remarks on nominalization. In Readings in English Transformational Grammar, ed. R. Jacobs \& P. Rosenbaum, 184-221. Waltham, Mass.: Ginn Press.

CHOMSKY, N. 1975. Reflections on language. New York: Pantheon.

CHOMSKY, N. 1981. Lectures on government and binding. Dordrecht: Foris.

CHOMSKY, N. 1986. Knowledge of language. New York: Praeger.

CHOMSKY, N. 1995. The Minimalist Program. Cambridge, Mass.: MIT Press.

CHOMSKY, N. 2000. Minimalist inquiries: The framework. In Step by step: Essays on minimalist syntax in honor of Howard Lasnik, ed. R. Martin, D. Michaels \& J. Uriagereka, 89-156. Cambridge, Mass.: MIT Press.

CHOMSKY, N. 2001. Derivation by phase. In Ken Hale: A life in language, ed. M. Kenstowicz, 1-52. Cambridge, Mass.: MIT Press.

CHOMSKY, N. 2002. Beyond explanatory adequacy. In Structures and beyond: Current issues in the theory of language, ed. A. Belletti, 104-131. Cambridge: Cambridge University Press.

CONTRERAS, H. 2003. Wh-movement without intermediate traces. Ms., University of Washington, Seattle.

EPSTEIN, S. D. 1994. The derivation of syntactic relations. Ms., Harvard University, Cambridge, Mass.

EPSTEIN, S. D. 1998. Overt scope marking and covert Verb Second. Linguistic Inquiry 29:181-229.

EPSTEIN, S. D. 1999. Un-principled syntax and the derivation of syntactic relations. In Working minimalism, ed. S. D. Epstein \& N. Hornstein, 317-346. Cambridge, Mass.: MIT Press.

EPSTEIN, S. D., E. GROAT, R. KAWASHIMA \& H. KITAHARA. 1998. A derivational approach to syntactic relations. Oxford: Oxford University Press.

EPSTEIN, S. D., A. PIRES \& T. D. SEELY. 2004. A theory of null complementizers and (the elimination of) the EPP in C. Ms., University of Michigan and Eastern Michigan University.

EPSTEIN, S. D. \& T. D. SEELY. 1999. SPEC-ifying the GF "subject": Eliminating A-chains and the EPP within a derivational model. Ms., University of Michigan and Eastern Michigan University; also presented at the LSA Summer Institute, 1999. 
EPSTEIN, S. D. \& T. D. SEELY, eds. 2002. Derivation and explanation in the Minimalist Program. Oxford: Blackwell.

EPSTEIN, S. D. \& T. D. SEELY. Forthcoming. Derivations in minimalism. Cambridge: Cambridge University Press.

FUKUI, N. \& M. SPEAS. 1986. Specifiers and projection. MIT Working Papers in Linguistics 8, ed. N. Fukui, T. R. Rapoport \& E. Sagey, 128-172. Cambridge, Mass.: MITWPL.

GROHMANN, K. K., J. DRURY \& J. C. CASTILLO. 2000. No more EPP. In Proceedings of the nineteenth West Coast Conference on Formal Linguistics, ed. R. Billerey \& B. D. Lillehaugen, 153-166. Somerville, Mass.: Cascadilla Press.

HALE, K. \& S. J. KEYSER. 1993. On argument structure and the lexical expression of syntactic relations. The view from Building 20: Essays in honor of Sylvain Bromberger, ed. K. Hale \& S. J. Keyser, 53-108. Cambridge, Mass.: MIT Press.

LASNIK, H. 1992. Case and expletives: Notes toward a parametric account. Linguistic Inquiry 23:381-405.

LASNIK, H. 1995. Case and expletives revisited: On Greed and other human failings. Linguistic Inquiry 26:615-633.

LASNIK, H. 1999. Syntactic structures revisited: Contemporary lectures on classic transformational grammar. Cambridge, Mass.: MIT Press.

LASNIK, H. 2001. A note on the EPP. Linguistic Inquiry 32:356-361.

LASNIK, H. 2002. On the Extended Projection Principle. Ms., University of Maryland, College Park.

LASNIK, H. \& J. URIAGEREKA. 1988. A course in GB syntax: Lectures on binding and empty categories. Cambridge, Mass.: MIT Press.

LIGHTFOOT, D. 2002. The form of innateness claims. Paper presented at the Linguistics Department Colloquium, University of Michigan, Ann Arbor.

MARTIN, R. 1999. Case, the EPP, and minimalism. In Working minimalism, ed. S. D. Epstein \& N. Hornstein, 1-26. Cambridge, Mass.: MIT Press.

MCCLOSKEY, J. 1997. Subjecthood and subject positions. In Elements of grammar: Handbook in generative syntax, ed. L. Haegeman, 197-235. Dordrecht: Kluwer.

MORO, A. 1997. The raising of predicates: Predicative noun phrases and the theory of clause structure. Cambridge: Cambridge University Press.

MYERS, S. 1984. Zero-derivation and inflection. In MIT Working Papers in Linguistics 7, ed. M. Speas \& R. Sproat, 53-69. Cambridge, Mass.: MITWPL.

ORMAZABAL, J. 1995. The syntax of complementation. Ph.D. dissertation, University of Connecticut, Storrs.

PESETSKY, D. 1991. Zero syntax: Part 2. Ms., MIT, Cambridge, Mass.

PESETSKY, D. \& E. TORREGO. 2001. T-to-C movement: Causes and consequences. In Ken Hale: A life in language, ed. M. Kenstowicz, 355-426. Cambridge, Mass.: MIT Press.

PESETSKY, D. \& E. TORREGO. 2004. Tense, Case, and the nature of syntactic categories. In The syntax of time, ed. J. Guéron \& J. Lecarme, 495-537. Cambridge, Mass.: MIT Press.

PIRES, A. 2001a. Clausal and TP-defective gerunds: Control without Tense. In Proceedings of NELS 31, ed. M. Kim \& U. Strauss, 389-406. Amherst, Mass.: GLSA Publications.

PIRES, A. 2001b. The syntax of gerunds and infinitives: Subjects, Case and control. Ph.D. dissertation, University of Maryland, College Park.

ROTHSTEIN, S. 1983. The syntactic form of predication. Ph.D. dissertation, MIT, Cambridge, Mass. 
80 Samuel David Epstein, Acrisio Pires, and T. Daniel Seely

STOWELL, T. 1981. Origins of phrase structure. Ph.D. dissertation, MIT, Cambridge, Mass.

WILLIAMS, E. 1980. Predication. Linguistic Inquiry 11:208-238.

Samuel David Epstein

University of Michigan

Linguistics Department $4096 F B-105$ S. State St. Ann Arbor, MI 48104-1285

USA

sepstein@umich.edu

Acrisio Pires

University of Michigan

Linguistics Department 4095FB - 105 S. State St. Ann Arbor, MI 48104-1285

USA

pires@umich.edu

T. Daniel Seely Eastern Michigan University Linguistics Program

Dept. of English Language and Literature Ypsilanti, MI 48197

USA

tseely@emich.edu 